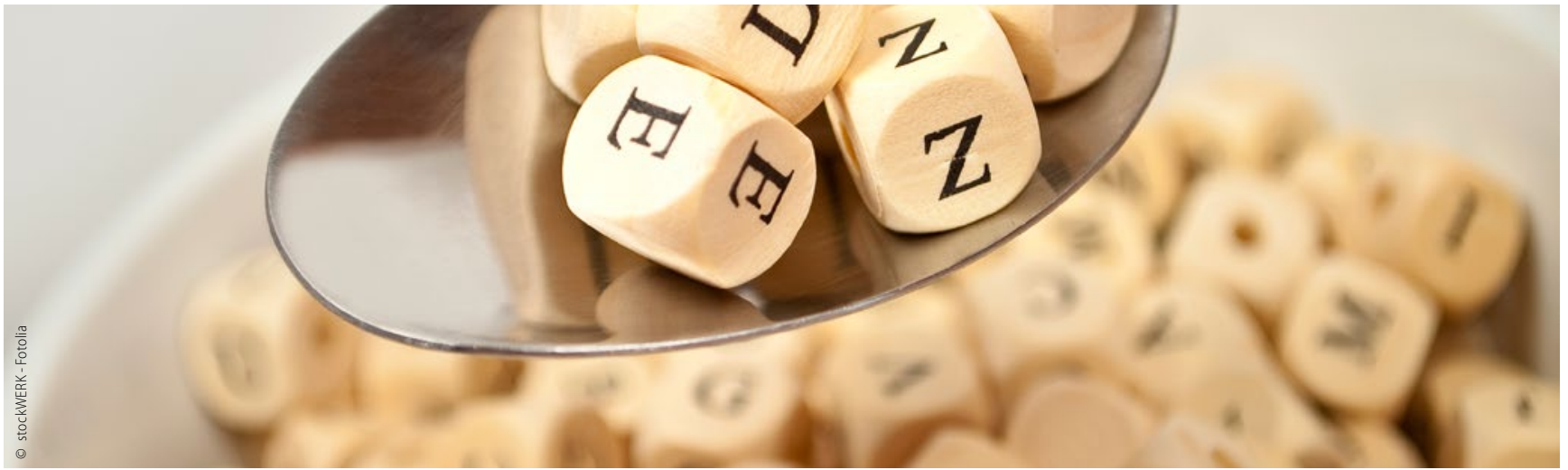

Buchhaltungs- $A B C$

\title{
E wie Einnahmekonten - Differenzierung und Funktion
}

\author{
Einnahme- oder Erlöskonten stellen den Gegenpol zu den Aufwands- beziehungsweise Kosten- \\ konten dar. Auf den Einnahmekonten werden beim Einnahmen-Überschuss-Rechner Erträge zu \\ dem Zeitpunkt gebucht, zu dem sie auf ein Finanzkonto (Kasse, Bank) fließen. Man findet sie im \\ SKR80/SKR03 im Bereich der Kontenklassen acht und zwei.
}

Differenzierte Erfassung bei der Kontierung verhilft einer Buchführung im Allgemeinen zu mehr Aussagekraft. Aber man darf es nicht übertreiben. Sind zum Beispiel zu viele Erlöskonten angelegt, werden die Ergebnisgruppen zu klein und haben keine Aussagekraft mehr. Vor allem muss darauf geachtet werden, dass die Anlage der Erlöskonten „eindimensional“ erfolgt.

\section{Differenzierung ist notwendig}

Eine Zuordnung muss immer eindeutig möglich sein. Gibt es mehrere passende Konten für den Ertrag, ist eine Verzerrung der Aussage der Buchhaltung wahrscheinlich. Eine Möglichkeit der Differenzierung besteht in der Verbuchung nach Herkunft der Mittel. Hierbei werden die Konten nach den „Absendern“ der Geldströme aufgeschlüsselt, beispielsweise als Einnahmen Patienten, Einnahmen Kassenzahnärztliche Vereinigung, Einnahmen Abrechnungsgesellschaft. Welche Leistung genau der jeweiligen Zahlung zugrunde lag ist dagegen mit weit höherer Genauigkeit als in der Buchhaltung der Praxissoftware zu entnehmen.

\section{Einnahmenkonto pro Umsatzsteuersatz}

Um einen späteren Abgleich mit der Umsatzsteuer-Voranmeldung zu erleichtern, sind pro Umsatzsteuersatz separate Konten zu erstellen, also in der Regel Umsatzkonten mit 19 Prozent und mit sieben Prozent. Die Anlage eines automatischen Steuerschlüssels für die Verbuchung der Umsatzsteuer ist nur bei den Konten möglich und sinnvoll, bei denen garantiert ist, dass ausschließlich Umsätze mit dem entsprechenden Umsatzsteuersatz hierauf verbucht werden.

Über die Einnahmen aus zahnärztlicher Tätigkeit hinaus gibt es noch Zinseinnahmen (Kontenklasse 2) und Erlöse aus Anla- genabgang, für die ausgewiesene Buchhaltungskonten geführt werden. Die eindeutige Beschriftung der Konten sollte immer nachvollziehbar sein (siehe betriebswirtschaftliche Auswertung), denn bei der Buchhaltung sollte immer das drin sein, was drauf steht.

Das in den Artikeln dargestellte Buchhaltungskonzept basiert auf der zahnarztspezifischen Buchhaltungssoftware fibu-doc und wird vom FVDZ unterstützt.

\section{Seminare}

Praxiskennzahlen: Verstehen - vergleichen - verbessern 04.12.2015 - Nürnberg

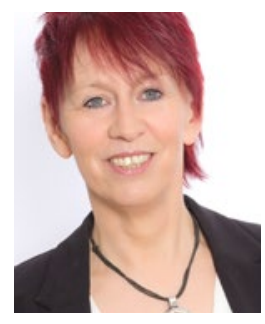

Barbara Mertens

www.fibu-doc.de 